\title{
DEVELOPMENTS IN STUDIES OF EARTHQUAKE RISK
}

\author{
R. D. Adams*
}

\begin{abstract}
Following recent developments in geophysics, analyses of earthquake risk should take full account of the tectonic setting of the regions concerned, of variations in soil properties, and of source characteristics of the earthquakes. New theories of global tectonics differentiate among various types of geophysically active areas. In particular, New Zealand's environment is closer to that of Japan and other west Pacific countries than to that of California, which is tectonically one of the least typical parts of the Pacific margin. The limitation of Californian earthquakes to depths in the upper crust, and their often established close lineations along surface traces of geological faults have resulted in the development of a refined process of quantitative risk analysis there, the techniques of which may not be appropriate in other areas. Small scale variations in soil characteristics cause variations in earthquake response which are often more significant in the evaluation of earthquake risk than regional differences in seismicity. Recent developments in seismic source theory show that a single parameter such as magnitude is not adequate to define source characteristics closely. With the additional determination of seismic moment, source parameters such as fault radius, fault displacement and stress drop can all be estimated. These source parameters define the expected shape of the source spectra, and thus the frequency characteristics of earthquakes that may be expected in different parts of an active area such as New Zealand.
\end{abstract}

\section{INTRODUCTION}

By the nature of their profession, engineers are expected to provide quantitative assessments of the factors affecting their work, and there has grown up, particularly in North America, a combination of geological, geophysical and statistical techniques which allocates definite figures to earthquake risk at specific places. This paper reviews some of the bases of these risk analyses, and in particular considers their relevance to New Zealand conditions. Variations in tectonic setting, in soil conditions and in source properties of the earthquakes themselves will be shown to be important factors in these studies.

\section{TECTONIC SETTING}

The long-known regional variations in seismicity over the Earth have only recently been explained in terms of tectonic movement. In the last decade, earlier ideas of continental drift have developed into fuller theories of "New Global Tectonics" or "Plate Tectonics", which offer an explanation of global earthquake distribution. (See for instance Bird and Isacks, 1972.) Fig. I shows the major plates, whose boundaries are marked by lines of growth along mid-oceanic ridges, by areas of underthrusting at typical oceanic-continental boundaries, or by sliding "transform faults". Most active seismic regions occur at plate

* Seismological Observatory, Geophysics Division, Department of Scientific and Industrial Research, Wellington. boundaries, but the type of boundary can determine the level and type of activity. Some earthquakes, however, do occur as "intra-plate" earthquakes, and these are often unusually large ones; examples are the Meckering earthquake in West Australia in 1968 and the New Madrid shocks in central U.S.A. in 1811-12.

The most active plate boundaries are those around the Pacific where one plate is being thrust under another. The details vary according to whether the area being underthrust is continental, like South America, a large island of continental structure, like Japan, the Philippines or New Zealand, or of more oceanic structure as in the Tonga-Kermadec region, but in all these areas earthquakes are related to an orderly pattern of gravity anomalies and volcanism, and earthquakes occur at all depths in the crust and deep into the mantle.

The spreading-ridge type of plate boundary is found at the south of the Pacific Plate, along the Pacific-Antarctic Ridge. On such boundaries the earthquakes are all shallow and the level of activity is lower than is generally found in areas of plate consumption.

The third type of plate boundary is typified by the regime in California. Here the Pacific Plate appears to be sliding parallel to the American Plate, along the San Andreas Fault system, which is considered a transform fault. The West Coast of North America is the only part of the Pacific perimeter to have such a tectonic environment, 
and must be considered the least typical tectonic regime of the circum-Pacific seismic areas. This difference will be reflected in the types of occurrence of earthquakes, and it may well be that techniques of seismic risk analysis developed in California are not appropriate elsewhere.

\section{Differences in Seismicity Patterns}

Differences in levels of seismicity among different regions aré not always appreciated. Maps of world earthquakes seldom have a uniform lower magnitude cutoff, and must be regarded as maps of earthquake detection capability as much as maps of relative numbers of earthquakes. Fig. 2 shows all earthquakes located by the United States agency ESSA in the period 1961-67. Differences in detection capabilities, however, seriously distort the seismicity pattern. For instance, most earthquakes of magnitude 3 in California will be plotted, while in general only those New Zealand earthquakes of magnitude 5 or greater will be detected by the U.S. agencies. This map does not lead one to suspect the true state of affairs, that the number of shallow earthquakes in California is only about half that in New Zealand.

The feature of Californian seismicity which differentiates it most from that of other circum-Pacific areas is its shallowness. Californian earthquakes generally originate in the top $10 \mathrm{~km}$ in the crust, and only rarely reach depths of $15 \mathrm{~km}$. This shallowness is reflected in felt intensities of Californian earthquakes, which are felt strongly over limited areas compared with wider, less severe, effects from deeper shocks. The shallowness of the foci also means that earthquakes can be closely associated with surface expressions of major faults, as is seen from the pattern of earthquakes in Fig. 3, which shows small earthquakes located by the U.S. Geological Survey in part of California during 1971. These in general follow the geological faults very closely. Such a pattern enables probability of earthquake occurrence to be linked with proximity to faults, although it takes no account of the possibility of a major earthquake occurring on a previously unrecognised fault, such as happened at San Fernando in 1971.

New Zealand's pattern of shallow seismicity, more typical of that found generally round the pacific, is quite different from California's. Fig. 4 shows the upper crustal earthquakes located in New Zealand from 1955 to 1966 , and the traces of the main faults. While our locations are not as accurate as those in California, there is no way in which these earthquakes can be confined to lineations near the faults. The reason for this difference lies in the depth range of New Zealand earthquakes: The earthquakes that are associated with known faults appear to be the very shallowest, at depths comparable with those of earthquakes in California, or even less. Such earthquakes, the two largest of magnitude 5.2 and 5.1, occurred near the clarence Fault in Marlborough in April 1973, and are thought to have been associated with a small surface breakage of the fault. Many of the shallow earthquakes in New Zealand, however, appear to be in the lower crust, at a depth of $20 \mathrm{~km}$ or more, where they bear little relation to surface geology. The depths are not great enough, however, to prevent these shocks from being felt strongly, and being of engineering significance.

Earthquakes that are classified as "intermediate" or "deep" are those with focal depths of $60 \mathrm{~km}$ or more. Such events do not produce strong surface effects unless their magnitude is particularly high, but they can produce minor damage over a very large area. The largest of New Zealand's recent deep earthquakes was a shock of magnitude $7,300 \mathrm{~km}$ beneath the Bay of Plenty in 1953, from which intensities of MM VI were reported over much of the North Island. Mantle earthquakes cannot be ignored in studies of earthquake risk.

Thus, in New Zealand distance from a known surface fault cannot be taken as an indication of immunity from earthquake effects. Recent examples of minor damaging earthquakes away from areas of main geological activity are the magnitude 5 shocks in Northland in 1963 and near Dunedin in 1974. The pattern of known active faults in areas of tectonic complexity cannot therefore be used as the only basis for quantitative studies of earthquake risk.

\section{Fault Displacement}

The dangers arising from displacement along the surface trace of a fault are often over-emphasised in comparison with the vibrational effects of the earthquakes. Fault displacement itself affects only those structures that directly straddle the segment that moves, whereas earthquake vibrations affect much larger areas. Californians in particular remember the impressive fault break that accompanied their 1906 earthquake, when movement occurred over a length of $300 \mathrm{~km}$, with a maximum displacement of over $5 \mathrm{~m}$ near San Francisco. Yet figures given by Bolt (in press) show that the expected risk from seismic shaking in California is about 300 times that expected from fault rupture. In California, where the movement on the plate boundary is one of predominantly horizontal sliding, strike slip movement such as that observed in 1906 is very common. There are regions of other types of fault movement, however, as evidenced by the San Fernando earthquake of 1971, which was accompanied by a reverse or thrusting type of faulting.

In New Zealand, on the other hand, observatory studies of earthquake mechanism show that most shallow earthquakes have sources of the reversed type. Field measurements of the 1929 Buller and 1968 Inangahua earthquakes showed movement of this type, but some other New Zealand earthquakes, such as the 1855 West Wairarapa and 1931 Napier shocks, have had a significant component of horizontal fault breakage as well as vertical movement. The Alpine Fault in the South Island shows a total horizontal displacement of about $500 \mathrm{~km}$, but has not been known to move in historical times. The length of expected surface breakage for large earthquakes of given magnitude can be expected to depend among other factors on the type of mechanism 
involved, and this will in general be subject to regional differences.

\section{Risk Maps}

Care must be taken in extrapolating past seismicity into the future. Thus, seismicity maps showing past activity may be contoured to show numbers of shocks, or rate of energy release in the past. These may not always be applicable to the future. Whereas it may be expected that general areas that have experienced earthquakes in the past will continue to have them in the future, it is likely that on a small scale it is the areas of low past seismicity in overall active areas that present the greatest risk. Unpublished maps of earthquake energy release in New Zealand from 1955 to 1967 show small inactive areas that could be correlated with the magnitude 7 Inangahua earthquake of May 1968, and the magnitude $5 \frac{1}{2}$ earthquake to the south-east of Wellington in November 1968. Similarly, the San Fernando earthquake in 1971 occurred in a region of comparative recent quietness in California. Seismicity maps therefore have to be interpreted with care as indicators of risk, and return periods calculated for small areas from past events alone may be misleading.

\section{SOIL AMPLIFICATION EFFECTS}

In New Zealand, as elsewhere, much emphasis has been placed on geographic variation of earthquake risk. In an area as small as that covered by New Zealand, however, geographic variations are minor compared with those that can be expected from variations in soil type. A clear example of this occurred in the Dunedin earthquake of April 1974 (Adams and Kean, 1974) in which intensities were at least one step higher in the low-lying alluvial areas in the south of the city, compared with the surrounding hills. This step of one intensity unit corresponds to that intended between the provisions for Zone $A$ and Zone $C$ of the New Zealand 1965 Model Bylaws. Similarly, earthquake vibrations during the Caracas earthquake of 1967 were increased by factors of up to nine in areas of poor ground (Espinosa and Algermissen, 1973).

Techniques are being used in New Zealand to microzone urban areas by a combination of geological, geophysical and soil surveys, backed up with readings of strong motion accelerations. Such a study has already been published for Wellington City (GrantTaylor et al., 1974), classifying the area into three types of zone in which vibrational effects may be expected to differ, and a topographic risk zone, where the steepness and composition of hillsides result in an added risk of slips. Analyses of the effects of past earthquakes are presented, and in general support the proposed zoning provisions. Similar work is underway at Gisborne and Dunedin, following damaging earthquakes there, and some investigations have been carried out at Christchurch.

The techniques employed use geological and geophysical surveys to establish the extent of areas of poor ground, and the depth to basement rock. The measurement of microseismic noise in various areas gives an indication of likely variations in amplitude during an earthquake, but these must be checked by strong-motion recordings for large accelerations for which the ground does not behave elastically.

\section{SOURCE CHARACTERISTICS}

Important advances have been made in the last few years concerning the understanding of the mechanism of the earthquake source. These have a bearing on the type of vibration that may be produced by earthquakes in different areas, and consequently on their effects on structures.

Until recently, magnitude has been the only measure of an earthquake's size, yet seismologists have been aware of great differences among earthquakes of a given magnitude, both in character of the records and in felt effects. These differences are now largely explained in terms of a spectral theory of earthquake dislocation sources arising from work by Brune and others (e.g., Brune, 1970), with significant contributions in New Zealand from Randall (1973) and more recently from Gibowicz (1975a, 1975b) in the application of the theory to the interpretation of observatory records.

Brune's theory considers an area of rupture on a fault plane that may be represented by a circle of radius $r$, over which a uniform dislocation $u$ occurs, resulting in a stress drop $\Delta \bar{\sigma}$, and release of seismic energy $E_{S}$. An important parameter is defined as seismic moment $\mathrm{M}_{0}=$ $\mu u A$, where A is the fault area $\left(\pi r^{2}\right) \frac{10}{a n d} \mu$, the rigidity of the rock, gives moment the correct dimensions of dyne-cm (or newtonmetres in SI units). According to this theory, the displacement spectrum of the radiated shear energy has a simple shape, being flat at the low frequencies, and falling off as the square of frequency at high frequencies. On a double logarithmic plot the spectrum is thus contained by two asymptotes, meeting at a "corner frequency". The level of the low-frequency asymptote is determined by the moment, and the corner frequency has a simple relationship with the idealized source radius $\underline{r}$.

Local magnitude $M_{L}$, is derived from the logarithm of the s-wave amplitude recorded on a Wood-Anderson seismograph of period $0.8 \mathrm{~s}$. In terms of spectral theory it defines the spectral displacement level at a frequency of $1.25 \mathrm{~Hz}$, and if both magnitude and moment are known all other source parameters can be determined. In fact, among the parameters moment, magnitude, source radius, fault displacement, stress drop, and seismic energy, a knowledge of any two is necessary and sufficient to specify all others. In particular, source radius is a function of the difference between moment and magnitude, except for earthquakes of radius less than $0.5 \mathrm{~km}$ (corresponding to a magnitude of about 3 ), for which moment and magnitude are the same, apart from a normalising factor. In the following discussion all sources are assumed to be greater than this.

Fig. 5 shows idealised source spectra for displacement, velocity and acceleration on double logarithmic plots. These are shown (a) for earthquakes of the same 
moment, but of different magnitude, and (b) for earthquakes of the same magnitude, but of different moment. In both cases the dotted curve has a lower corner frequency and the corresponding earthquake a larger source size. In case (a) the earthquake represented by the dotted curve has a lower magnitude, a larger source size, and therefore a lower displacement across the fault to produce the given moment. In case (b), where both earthquakes have the same magnitude, that represented by the dotted curve has both a larger moment and a larger source size.

Fig. 5 shows that the moment determines the low-frequency level of the displacement spectrum and that the source becomes deficient in high frequencies above the corner frequency. The velocity spectrum peaks at the corner frequency. For the acceleration spectrum the high-frequency level is determined by the magnitude, and accelerations fall off at frequencies lower than the corner frequency. Thus, the relationship of moment to the lowfrequency displacement spectrum is similar to that of magnitude to the high-frequency acceleration spectrum.

Spectral analysis is most directly achieved by computer analysis of digital magnetic-tape recordings of local earthquakes. A simpler method devised by Brune et al (1963), however, enables moment to be found directly from the envelope of surface waves recorded on standard long-period seismographs. When this is combined with magnitudes obtained from short-period instruments, all spectral source characteristics can be determined.

Gibowicz (1975a) lists spectral source parameters for some 350 New Zealand earthquakes since 1965, and by invoking further information from aftershock distributions, has obtained similar parameters for past New zealand earthquakes of note. Table 1 lists this information for selected earthquakes. Among the parameters listed is source radius, which for shallow earthquakes can be related to corner frequency by the equation

$$
f_{0}=\frac{1.4}{r} \text {. }
$$

For earthquakes of large source size, such as the Hawke's Bay shock of 1931, accelerations generated are constant for all periods up to about $25 \mathrm{~s}$. The Bay of Plenty earthquakes of March 1974, although more than two magnitudes smaller, will be similarly rich in long-period energy, by virtue of their large size. On the other hand, small sources will have their energy concentrated at high frequencies. For the Dunedin earthquake of April 1974, for instance, the corner frequency corresponds to a period of about $0.7 \mathrm{~s}$, and the earthquake will be deficient in energy at periods larger than this.

As a consequence of this new understanding of earthquake mechanism it is now no longer appropriate to consider simple relationships between any two source parameters. For instance, Fig. 6 shows a plot, taken from Gibowicz' results, of source dimensions of some New Zealand earthquakes against magnitude. Also shown is a singlevalued relationship given by Housner (1970).
The scatter of source size for any given magnitude is large, being about a factor of ten. Superimposed on the plot are lines of equal stress drop, which show that Housner's line is not far removed from the expected relationship if all earthquakes resulted from a stress drop of 10 bars.

When results from a limited region only are displayed, more consistency is evident. Fig. 7 gives a similar plot of magnitude against source size for aftershocks of the 1968 Inangahua earthquake. Here the range of size for any particular magnitude is much less, but it is also evident that shocks of increasing magnitude result from increasing stress drop.

Regional differences in source characteristics in New Zealand have been studied by Gibowicz and Hatherton (in press). The parameter they have chosen to discuss is fault displacement, normalised to a standard earthquake moment. Their plot of regional variations is reproduced in Fig. 8. Areas of large displacement indicate small, compact, high stress-drop sources in strong rock, whereas those of low displacement indicate large, low stress-drop sources in weak or fractured rock. These results have obvious tectonic implications, but are also of engineering significance. For earthquakes of given energy release, those in areas of predominantly large displacement, such as Fiordland, Nelson, Manawatu, Taranaki, and eastern Bay of Plenty will be relatively lacking in long-period energy. On the other hand, earthquakes in areas of predominantly small displacement, such as the central South Island, the central volcanic regions of the North Island, the western Bay of Plenty, and offshore areas to the east of Gisborne and Wairarapa, will have a relatively greater proportion of long-period energy.

The engineering implications of such differences are obvious. The April 1974 earthquake near Dunedin was rich in highfrequency energy such as would affect small stiff structures. Earthquakes closer to Auckland, such as those felt there in March 1974, that originated in the Bay of Plenty, are likely to be rich in longperiod energy, such as would excite taller, more flexible, structures.

\section{CONCLUSIONS}

Variations in tectonic setting, in soil conditions, and in recently elucidated source properties of earthquakes themselves are all factors that must be taken into account in the assessing of earthquake risk. In particular, techniques developed in one region should not be applied uncritically in other areas, and it is not appropriate for results obtained in one area to be used in another. In New Zealand, as in other places, earthquake risk analyses must take full account of local conditions.

\section{REFERENCES}

Adams, R. D. and Hatherton, T. 1973. Seismological and Geothermal Research in New Zealand. Nature, 246, 262-4. Adams, R. D. and Kean, R. J. 1974. The 
Dunedin Earthquake, 9 April, 1974. Part 1: Seismological studies. Bull. N.z. Nat. Soc. Earthquake Eng. 7, 115-22.

Barazangi, M. and Dorman, J. 1969. World Seismicity Maps compiled from ESSA, Coast and Geodetic Survey, Epicenter Data, 1961-67. Bull. Seismol. Soc. Amer. 59, 369-80.

Bird, J. M. and Isacks, B. (Editors) 1972. "Plate Tectonics, Selected Paper from the Journal of Geophysical Research", American Geophysical Union, Washington, D.C.

Bolt, B. A. (in press). "Geological Hazards". Brune, J. N. 1970. Tectonic Stress and the Spectra of Seismic Shear Waves from Earthquakes. J. Geophys. Res. 75, 49975009 .

Brune, J. N., Espinosa, A. and Oliver, J. 1963. Relative Excitation of Surface Waves by Earthquakes and Underground Explosions in the California-Nevada region. J. Geophys. Res. 68, 3501-13.

Espinosa, A. F. and Algermissen, S.T. 1972. A Study of Soil Amplification Factors in Earthquake Damage Areas, Caracas, Venezuela. NOAA Technical Report ERL 280 - ESI 31 .

Gibowicz, S. J. 1975a. Determination of Seismic Moment and Related Source Parameters of Shallow Local Earthquakes from Wellington Records. N.Z. Dept. Sci. Industr. Res., Geophysics Division Report
No. 99.

Gibowicz, S. J. 1975b. Variation of Source Properties: The Inangahua, New Zealand, Aftershocks of 1968. Bull. Seismol. Soc. Amer. 65 (1).

Gibowicz, S. J. and Hatherton, T. (in press). Source Properties of Shallow Earthquakes in New Zealand and their Tectonic Associations. Geophys. J. Roy. Astron. Soc.

Grant-Taylor, T. L., Adams, R. D., Hatherton, T., Milne, J. D. G., Northey R. D. and Stephenson, W. R. 1974. Microzoning for Earthquake Effects in Wellington, N.Z. N.z. Dept. Sci. Industr. Res., Bulletin 213.

Housner, G. W. 1970. Strong Ground Motion. In "Earthquake Engineering". (Ed. R. L. Wiegel.) Prentice-Hall, Inc., Englewood Cliffs, N. J.

Lee, W.H.K., Meagher, K. L., Bennett, R. E. and Matamoros, E. E. 1972. Catalogue of Earthquakes Along the San Andreas Fault System in Central California for the year 1971. U.S. Geological Survey, National Center for Earthquake Research. Open-file Report.

Le Pichon, X. 1968. Sea-Floor Spreading and Continental Drift. J. Geophys. Res. 73 , 3661-97.

Randall, M. J. 1973. The Spectral Theory of Seismic Sources. Bull. Seismol. Soc. Amer. 63, 1133-44.

TABLE 1.

SOURCE PARAMETERS OF SELECTED NEW ZEALAND EARTHQUAKES

(AFTER GIBOWICZ， 1975A)

\begin{tabular}{|c|c|c|c|c|}
\hline Earthquake & Date & $\underset{M_{L}}{\operatorname{Magnitude}}$ & $\begin{array}{c}\text { Source Radius } \\
(\mathrm{km})\end{array}$ & $\begin{array}{c}\text { Fault Displacement } \\
(\mathrm{cm})\end{array}$ \\
\hline Hawke's Bay & $1931 \mathrm{Feb} 2$ & 7.8 & 35.5 & 624 \\
\hline Pahiatua & 1934 Mar 5 & 7.5 & 29.8 & 314 \\
\hline Wairarapa & 1942 Jun 24 & 7.0 & 14.8 & 100 \\
\hline Wairarapa & 1942 Dec 2 & 6.0 & 7.0 & 11.2 \\
\hline Fiordland & 1960 May 24 & 7.0 & 13.8 & 104 \\
\hline Westport & 1962 Mar 4 & 6.2 & 11.0 & 16.5 \\
\hline Seddon & 1966 Apr 23 & 6.0 & 14.6 & 10.3 \\
\hline Inangahua & 1968 May 23 & 7.1 & 19.0 & 129 \\
\hline Te Aroha & 1972 Jan 8 & 5.1 & 16.0 & 1.3 \\
\hline Bay of Plenty & $1974 \mathrm{Feb} 28$ & 5.6 & 43.0 & 4.0 \\
\hline Dunedin & 1974 Apr 9 & 4.6 & 0.9 & 1.4 \\
\hline Taranaki & 1974 Nov 5 & 6.2 & 6.0 & 17.5 \\
\hline Taranaki & 1974 Nov 5 & 5.5 & 4.0 & 4.1 \\
\hline
\end{tabular}




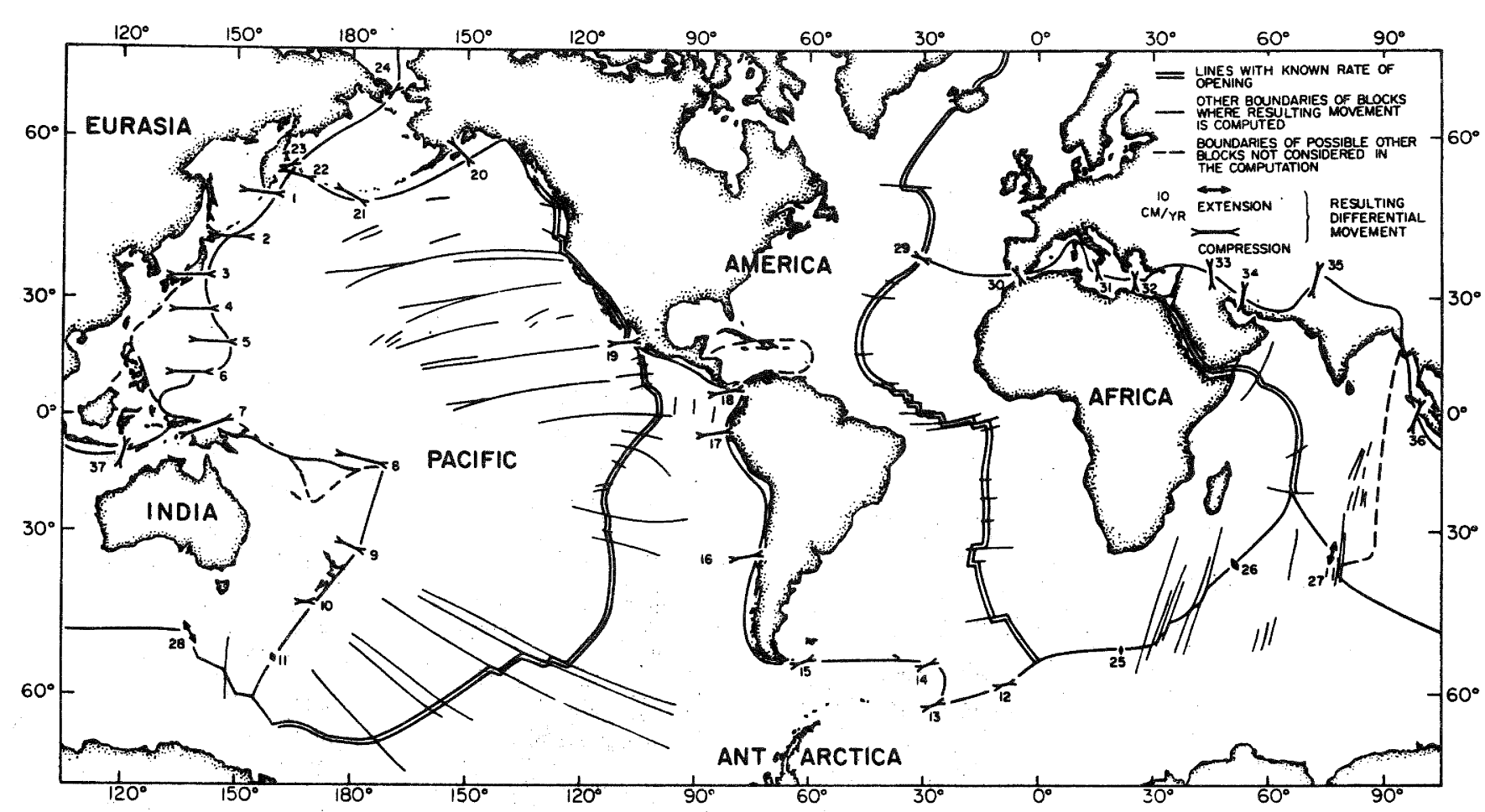

FIGURE 1: THE SIX MAJOR PLATES OF THE EARTH'S SURFACE, AND THEIR BOUNDARIES. (FROM LE PICHON, 1968.)

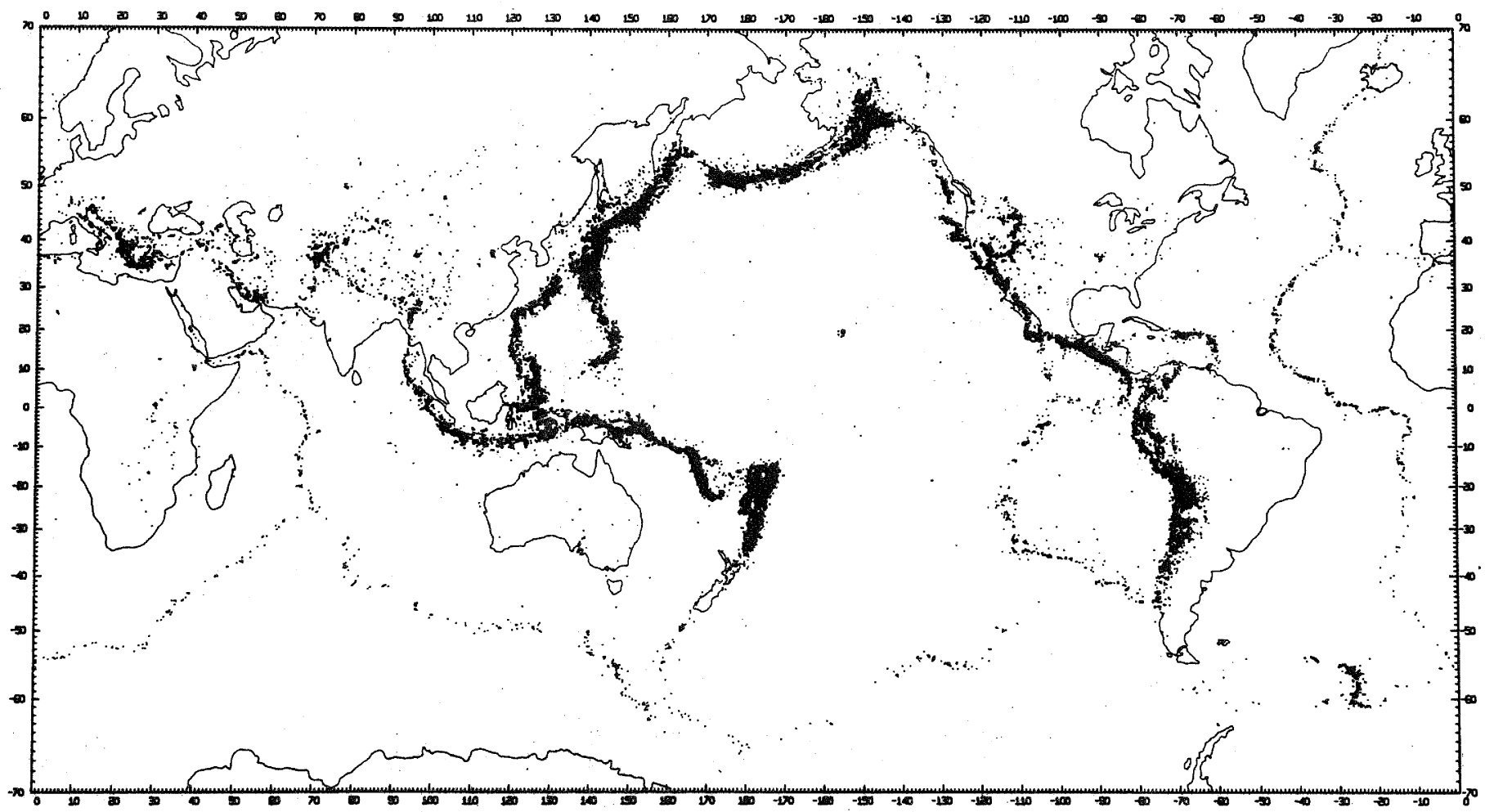




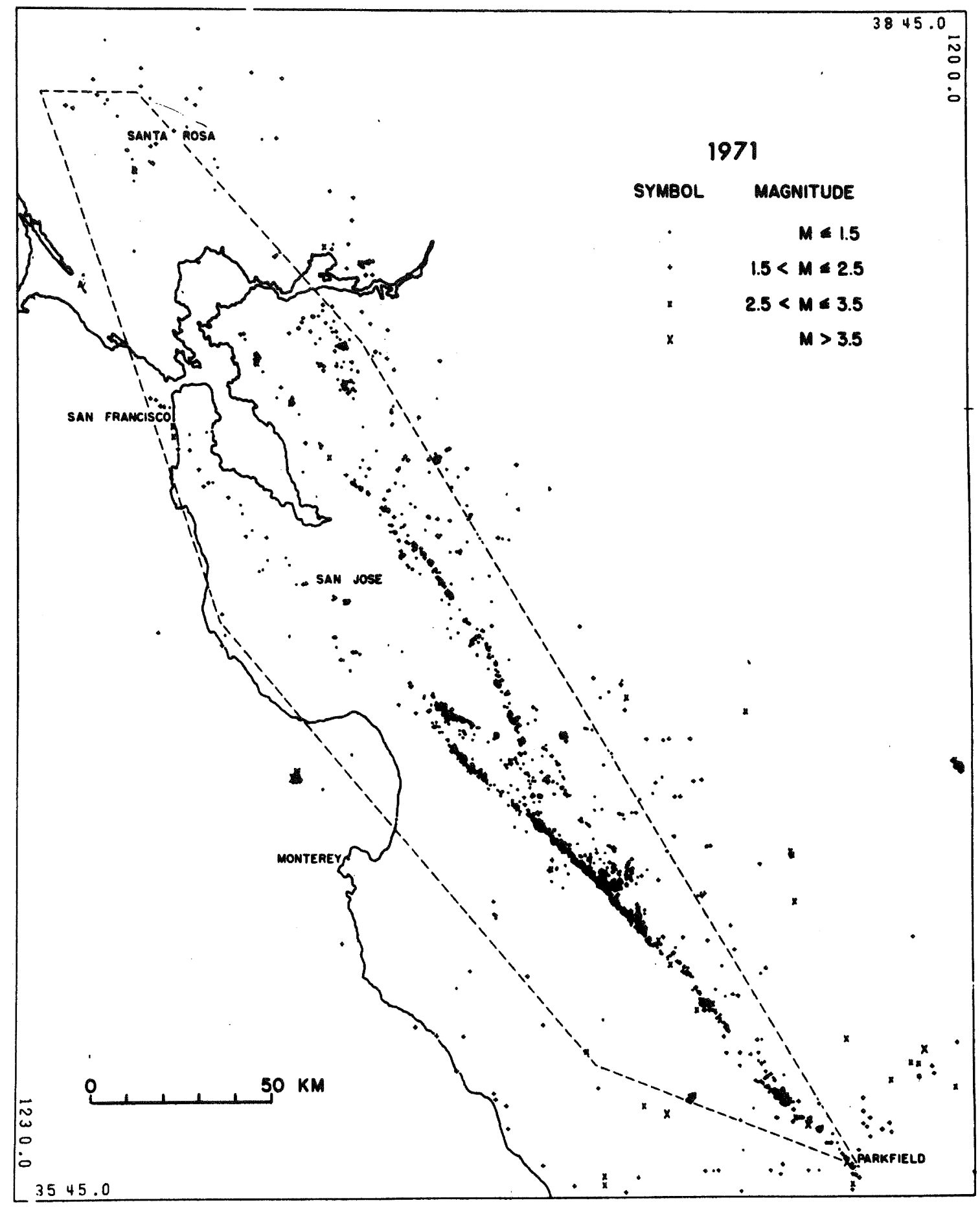

FIGURE 3: EARTHQUAKES LOCATED IN CENTRAL CALIFORNIA BY U.S. GEOLOGICAL SURVEY, 1971. (FROM LEE ET AL.,1972.) 


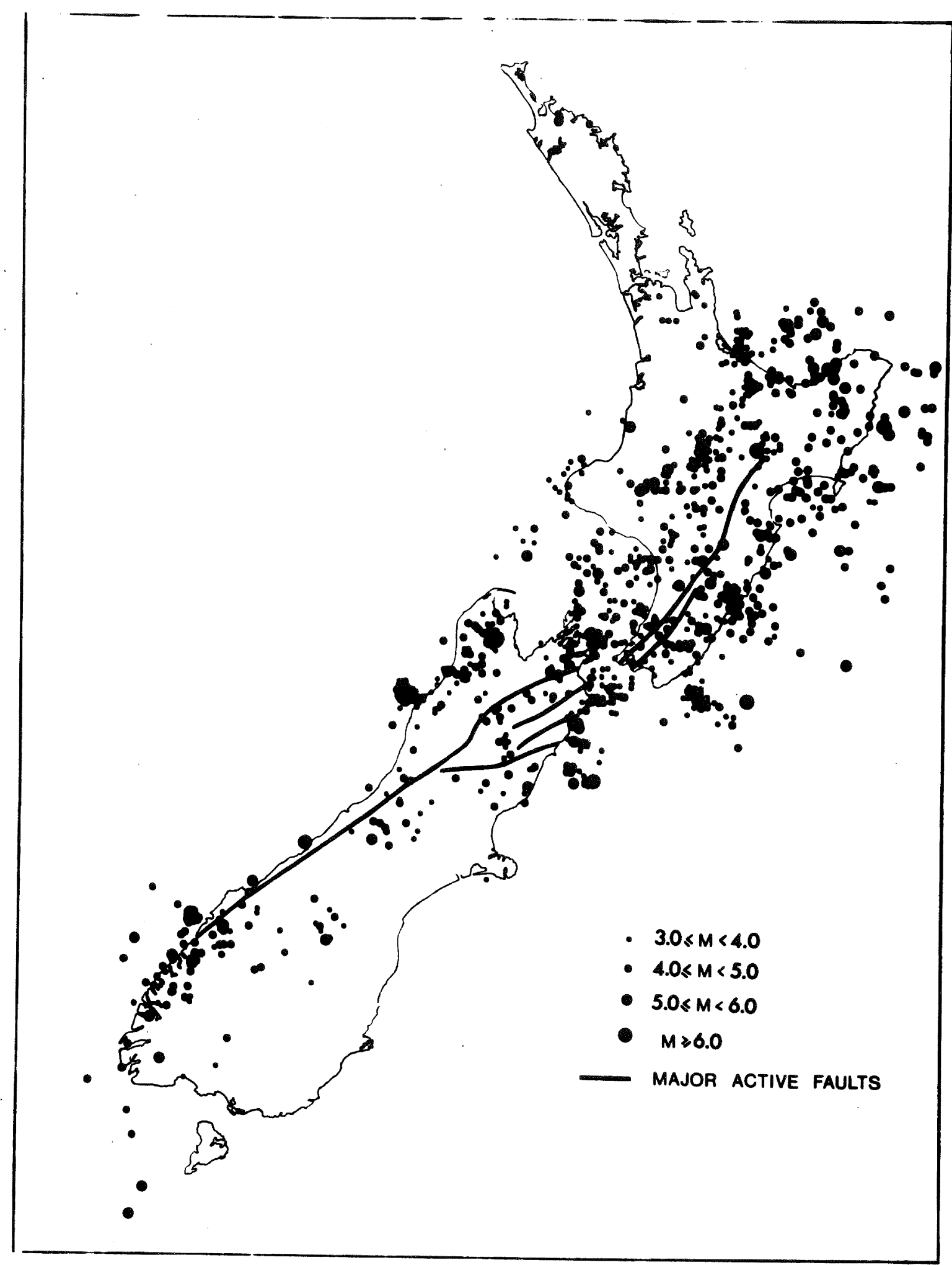

FIGURE 4: UPPER CRUSTAL EARTHQUAKES LOCATED IN NEW ZEALAND 1955-66. (FROM ADAMS AND HATHERTON, 1973.) 
(a)

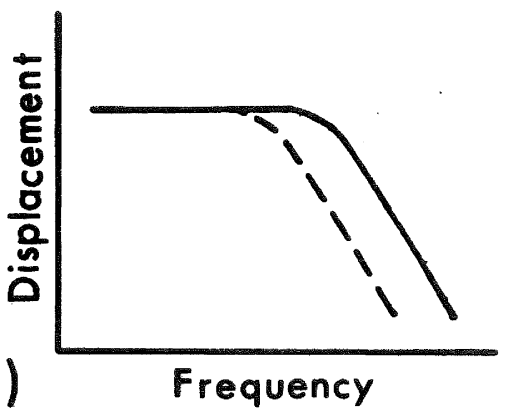

(b)

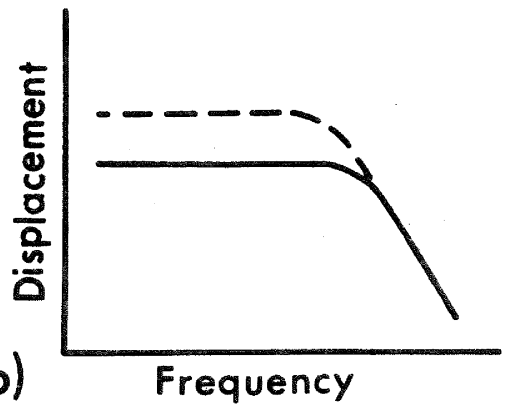

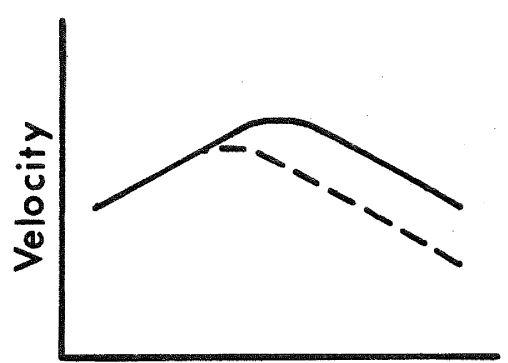

Frequency

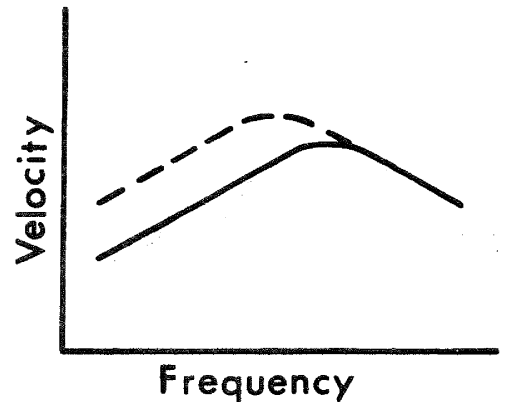

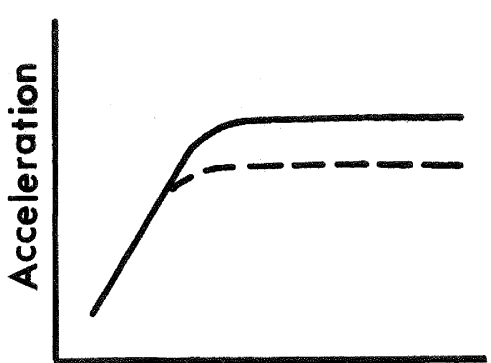

Frequency

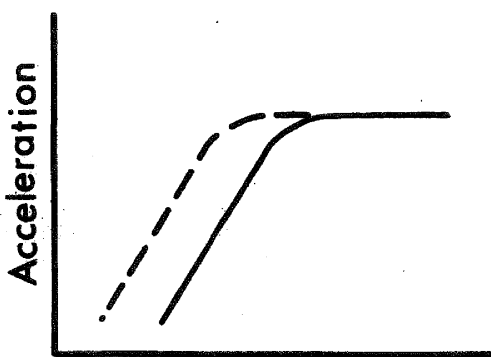

Frequency

FIGURE 5: DOUBLE LOGARITHMIC PLOTS OF IDEALIZED SOURCE SPECTRA

(a) FOR EARTHQUAKES WITH SAME MOMENT BUT DIFFERENT MAGNITUDE AND

(b) FOR EARTHQUAKES WITH SAME MAGNITUDE BUT DIFFERENT MOMENT.

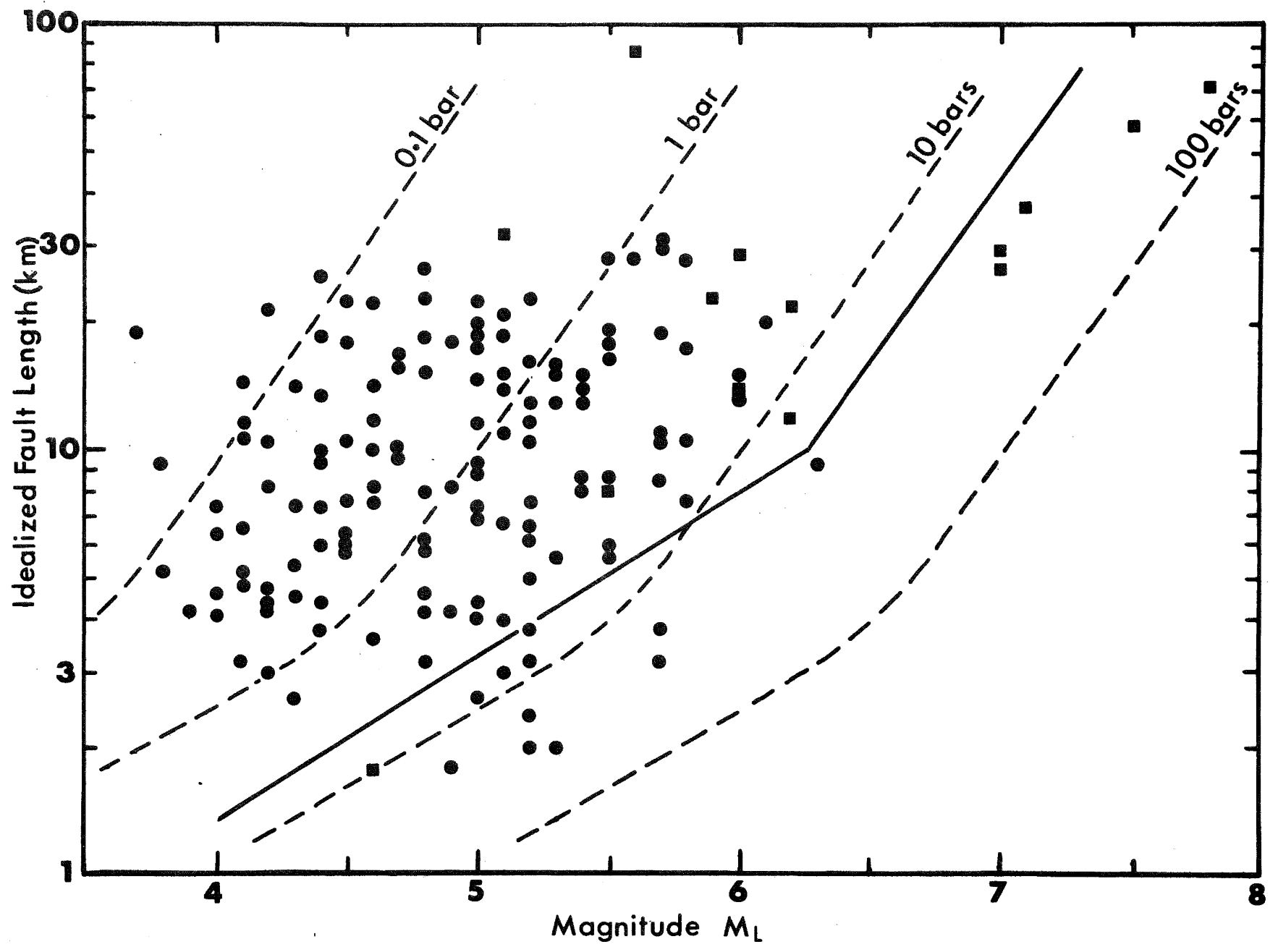

FIGURE 6: PLOT OF IDEALIZED FAULT LENGTH (2r) AGAINST MAGNITUDE, DERIVED FROM MEASUREMENTS OF MOMENT OF NEW ZEALAND EARTHQUAKES.

EARTHQUAKES DETAILED IN TABLE 1 ARE SHOWN BY SQUARE SYMBOLS.

SOLID LINE REPRESENTS RELATIONSHIP GIVEN BY HOUSNER (1970). 


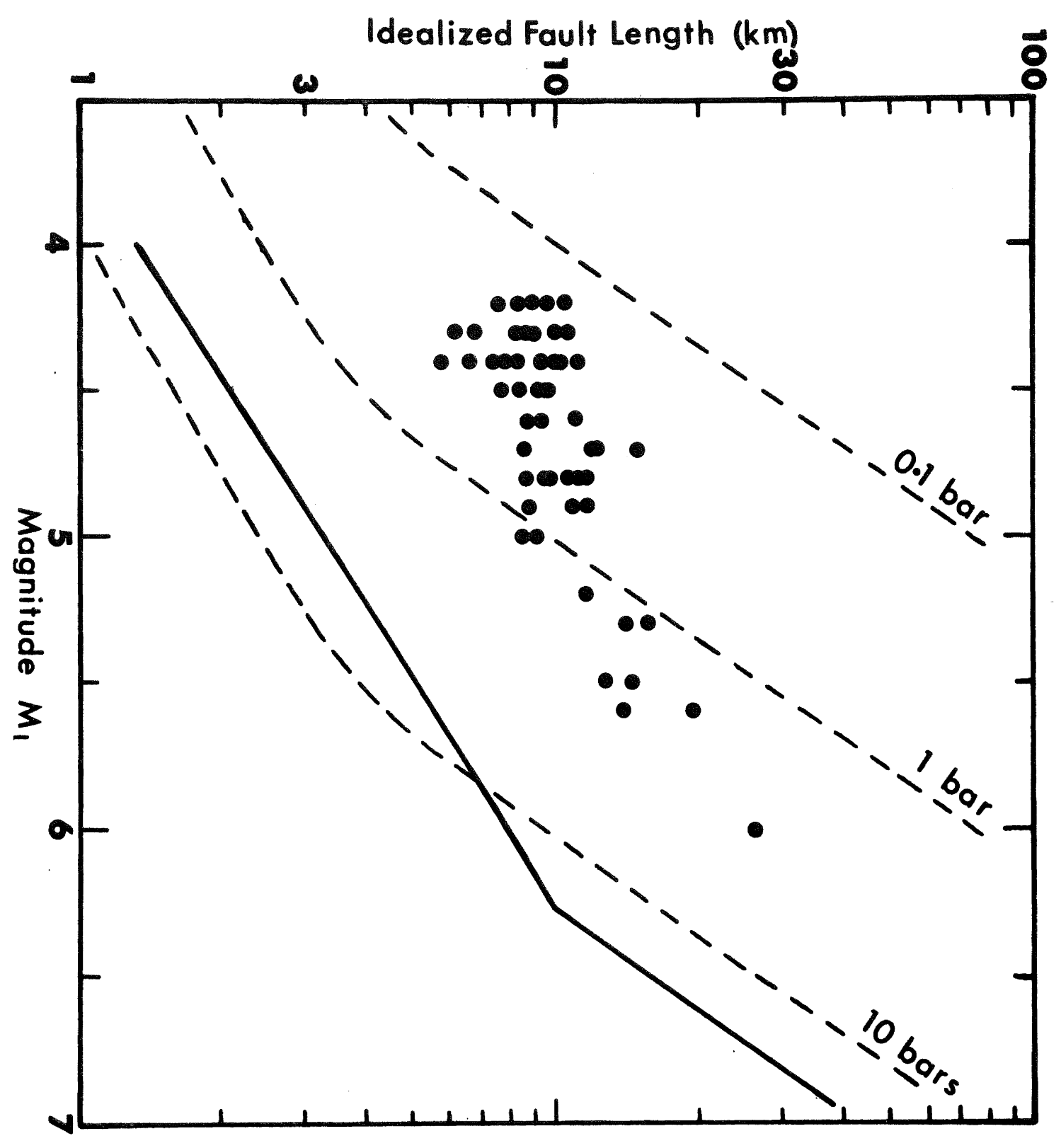

FIGURE 7: PLOT OF IDEALIZED FAULT LENGTH (2r) AGAINST MAGNITUDE, DERIVED FROM MEASUREMENTS OF MOMENT OF INANGAHUA AFTERSHOCKS. SOLID LINE REPRESENTS RELATIONSHIP GIVEN BY HOUSNER (1970.) 


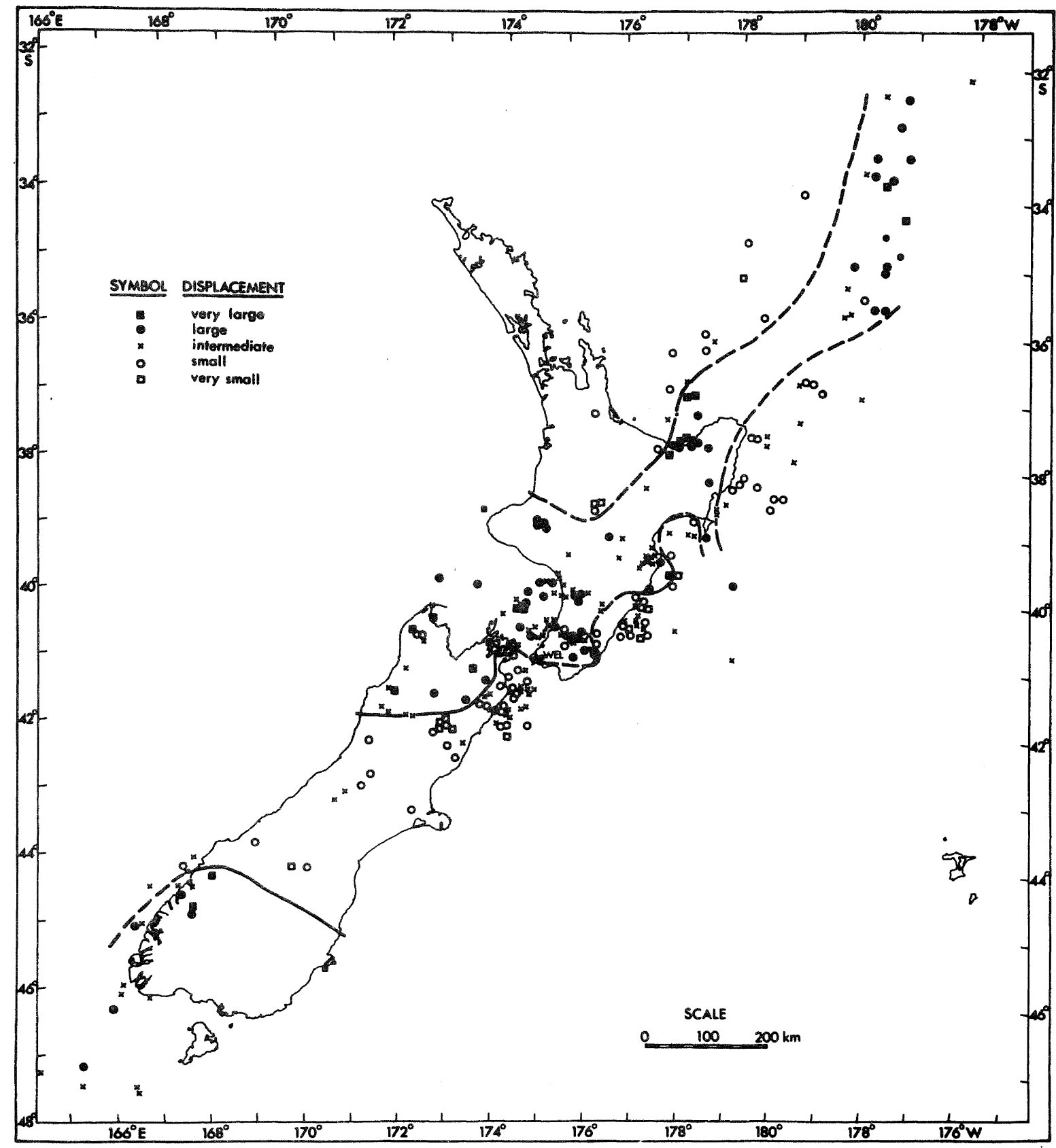

FIGURE 8: REGIONS OF NEW ZEALAND AREA WITH DIFFERENT CHARACTERISTIC FAULT DISPLACEMENT FOR EARTHQUAKES OF GIVEN MOMENT. LARGE DISPLACEMENT IMPLIES COMPACT SOURCE DIMENSION AND HIGH STRESS DROP, AND CONVERSELY. (FROM GIBOWICZ AND HATHERTON, 1975.) 